\title{
HUBUNGAN TINGKAT KEKUATAN OTOT DENGAN PRESTASI ATLET CABANG OLAHRAGA JUDO PADA PEKAN OLAHRAGA NASIONAL (PON) XVIII 2012 DI RIAU
}

\author{
Vita Murniati Tarawan L ${ }^{1}$, Rizky Aji Pambudi ${ }^{1}$, Vitriana Biben ${ }^{2}$ \\ ${ }^{1}$ Departemen Anatomi, Fisiologi, dan Biologi Sel, Fakultas Kedokteran, Universitas Padjadjaran, Bandung, Indonesia, \\ 2Departemen Ilmu Kedokteran Fisik dan Rehabilitasi, Fakultas Kedokteran, Universitas Padjadjaran/RSUP Dr. Hasan \\ Sadikin, Bandung, Indonesia.
}

\begin{abstract}
Judo is described as a physical contact sport. A judo athlete should try to make the movement of throwing, slamming, and holding the opponent's strength during the game. To perform the technique well, muscle strength is important in judo athlete. As one of the components of physical fitness in athletes, muscle strength has an important role for the judo athlete to maximize their performance and have their best achievement. Therefore, this study aims to determine the relationship of muscle strength level of judo athlete with their achievement in Pekan Olahraga Nasional (PON) XVIII 2012 in Riau. A cross-sectional study using analytical method was done on 19 Judo athletes as subjects. Data are collected from secondary data as a result of muscle strength examination measured by push, pull, and leg dynamometer, conducted by Komite Olah Raga Nasional (KONI) West Java. Judo athletes who participated Pekan Olah Raga Nasional (PON) XVIII 2012 championship in Riau were included while athletes who injured were excluded. In this study judo athletes who won medals (got achievement) was 7 athletes, while those who did not win medals (did not get the achievement) was 12 athletes. Significance value (p-value) for the relationship of muscle strength with judo athlete's achievement as measured by push dynamometer was 0.764, pull dynamometer was 0.570 and leg dynamometer was 0.132. In conclusion, there is no significant relationship between the level of muscle strength with the judo athlete's achievement on Pekan Olah Raga Nasional (PON) XVIII 2012.
\end{abstract}

Keywords: achievement, judo athletes, muscle strength

Korespondensi: Rizky Aji Pambudi. Departemen Anatomi, Fisiologi, dan Biologi Sel, Fakultas Kedokteran Universitas Padjadjaran. Jalan Raya Jatinangor Km 21, Sumedang, Jawa Barat, Indonesia. 


\section{PENDAHULUAN}

Pada pelaksanaan Pekan Olahraga Nasional (PON) XVIII 2012 di Riau, Kontingen Jawa Barat berhasil mendapatkan 27 medali dalam cabang olahraga kontak fisik. Judo berhasil mendapatkan total 9 medali dari 10 kelas yang dipertandingkan dan menjadi olahraga kontak fisik yang diunggulkan serta paling banyak menyumbangkan medali.

Judo digambarkan sebagai olahraga kontak fisik. Seorang atlet judo harus mencoba untuk melakukan pergerakan melempar, membanting, dan menahan kekuatan lawan selama pertandingan. Dalam judo, pergerakan dan kekuatan otot menjadi bagian penting serta merupakan salah satu komponen kebugaran fisik pada atlet, sehingga diduga memiliki peran penting bagi atlet untuk berprestasi dengan maksimal. ${ }^{2,3}$

Penelitian sebelumnya menunjukkan peran penting komponen kekuatan otot dalam olahraga judo. Salah satunya adalah penelitian yang dilakukan National Center of Sciences and Sport Medicine, Tunis, Tunisia (2014) yang mengukur kekuatan otot pada bahu dan tungkai bawah atlet judo mempergunakan isokinetic dynamometer. Hasil penelitian tersebut menyatakan bahwa kekuatan otot menjadi faktor penentu utama atlet judo untuk berprestasi. ${ }^{4}$

Penelitian University of Novi Sad, Serbia (2015), menyatakan bahwa atlet judo yang meraih medali (elit) pada kejuaraan judo kategori half-heavy weight memiliki kekuatan otot yang lebih tinggi dibandingkan dengan atlet yang tidak meraih medali (sub-elit). ${ }^{2}$ Sementara itu berdasarkan Perhimpunan Ahli Ilmu Faal Olahraga Indonesia Tahun 2014, seorang atlet dapat meraih prestasi di tingkat nasional apabila kekuatan otot yang dimiliki berada minimal pada kategori baik. ${ }^{5}$

Berdasarkan hal tersebut, penelitian ini ditujukan untuk mengetahui hubungan tingkat kekuatan otot dengan prestasi atlet cabang olahraga Judo pada PON XVIII 2012 di Riau. Hasil penelitian ini diharapkan memberikan gambaran rerata tingkat kekuatan atlet judo dan memberikan data dasar untuk acuan atlet judo dalam meningkatkan kekuatan otot yang dimilikinya.

\section{METODE}

Penelitian ini menggunakan metode penelitian analitik dengan pendekatan potong lintang (cross-sectional). Data penelitian menggunakan data sekunder yang tercatat dalam "Laporan Hasil Tes Kondisi Fisik (Tes Fisiologi) Atlet Pelatda PON XVIII Riau KONI Jawa Barat". Data penelitian merupakan hasil pemeriksaan kekuatan otot yang dilakukan Komite Olahraga Nasional Indonesia (KONI) Jawa Barat pada atlet judo yang mengikuti kejuaraan PON XVIII 2012 Riau.

Variabel terikat pada penelitian ini adalah prestasi atlet. Prestasi atlet didefinisikan sebagai atlet yang mampu meraih medali emas, perak, atau perunggu. Kekuatan otot atlet judo yang merupakan bagian dari uji kebugaran fisik merupakan variabel bebas pada penelitian ini. Variabel ini diukur menggunakan dynamometer, yang diukur melalui 3 cara pengukuran. Pengukuran kekuatan dorong otot lengan dan tubuh atas (push dynamometer), kekuatan menarik otot lengan dan tubuh atas (pull dynamometer), serta kekuatan otot tungkai (leg dynamometer). Data besar kekuatan otot tersebut dicatat dan dikelompokkan menjadi 5 kategori yaitu kurang, cukup, baik, baik sekali, dan sempurna berdasarkan kategori yang telah ditetapkan oleh Perhimpunan Ahli Ilmu Faal Olahraga Indonesia (Tabel 1 dan 2).

Sampel penelitian diperoleh dengan teknik total sampling dengan kriteria inklusi yaitu data atlet judo yang menjadi kontingen Jawa Barat pada PON XVIII 2012 Riau dan mengikuti pemeriksaan fisik pada bulan Januari tahun 2012. Data atlet judo yang tidak lengkap dikarenakan mengalami cedera pada bulan Januari tahun 2012 dieksklusi dari sampel penelitian. Data kemudian dianalisis melalui uji regresi logistik, dengan tingkat signifikansi hasil uji $\mathrm{p}<0,05$. Analisis dilakukan dengan perangkat lunak komputer Statistical Product and Service Solution (SPSS) 2.0.

Penelitian dilaksanakan pada bulan Agustus 2017 di KONI Jawa Barat, Bandung setelah mendapat persetujuan Komite Etik Penelitian Kesehatan Fakultas Kedokteran Univesitas Padjadjaran. 
Tabel 1 Standar Kekuatan Otot Atlet Judo Putra Berdasarkan Perhimpunan Ahli Ilmu Faal Olahraga Indonesia

\begin{tabular}{|c|c|c|c|c|c|c|}
\hline \multirow{2}{*}{$\begin{array}{c}\text { Komponen } \\
\text { Kekuatan (kg) }\end{array}$} & \multirow{2}{*}{$\begin{array}{c}\text { Teknik } \\
\text { Pengukuran }\end{array}$} & \multicolumn{5}{|c|}{ Kategori } \\
\hline & & Kurang & Cukup & Baik & $\begin{array}{c}\text { Baik } \\
\text { Sekali }\end{array}$ & Sempurna \\
\hline Otot lengan dan bahu & $\begin{array}{c}\text { Hand Dynamometer } \\
\text { (Pull \& Push Dynamometer) }\end{array}$ & $23-29$ & $30-36$ & $37-43$ & $44-50$ & $\geq 51$ \\
\hline Otot punggung & Back Dynamometer & $59-74,5$ & $80-100,5$ & $101-122$ & $122,5-143$ & $\geq 143,5$ \\
\hline Otot tungkai & Leg Dynamometer & $77-145$ & $146-214$ & $215-282$ & $\geq 283$ & \\
\hline
\end{tabular}

Tabel 2 Standar Kekuatan Otot Atlet Judo Putri Berdasarkan Perhimpunan Ahli Ilmu Faal Olahraga Indonesia

\begin{tabular}{lcrrrrr}
\hline \multicolumn{1}{c}{$\begin{array}{c}\text { Komponen } \\
\text { Kekuatan (kg) }\end{array}$} & $\begin{array}{c}\text { Teknik } \\
\text { Pengukuran }\end{array}$ & Kurang & Cukup & Baik & $\begin{array}{l}\text { Baik } \\
\text { Sekali }\end{array}$ & Sempurna \\
\cline { 3 - 8 } & Hand Dynamometer & $9-17$ & $18-26$ & $27-35$ & $36-44$ & $\geq 45$ \\
Otot lengan dan bahu & $\begin{array}{c}\text { (Pull \& Push Dynamometer) } \\
\text { Back Dynamometer }\end{array}$ & $29,5-39$ & $39,5-49,5$ & $50-60$ & $60,5-70$ & $\geq 70,5$ \\
Otot punggung & Leg Dynamometer & $6-64$ & $65-123$ & $124-182$ & $183-241$ & $\geq 242$ \\
Otot tungkai & & & & & &
\end{tabular}

Tabel 3. Karakteristik Dasar Atlet Judo Kontingen Jawa Barat pada PON XVIII 2012 Riau

\begin{tabular}{lcr}
\hline \multirow{2}{*}{ Karakteristik } & \multicolumn{2}{c}{ Nilai Karakteristik } \\
\cline { 2 - 3 } & rerata \pm SD & N \\
\hline Usia (tahun) & $24,63 \pm 5,145$ & 19 \\
Jenis Kelamin & & \\
$\quad$ & & 9 \\
$\quad$ Laki-laki (n) & & 10 \\
Perempuan (n) & & 19 \\
Tinggi Badan $(\mathrm{cm})$ & $163,58 \pm 10,096$ & 19 \\
Berat Badan $(\mathrm{kg})$ & $73,295 \pm 5,0846$ & \\
\hline
\end{tabular}

HASIL

Dari total 19 sampel penelitian ditemukan karakteristik dasar meliputi usia, jenis kelamin, tinggi badan, dan berat badan. Tabel 3 menunjukkan rerata usia, tinggi badan, dan berat badan. Rerata usia dari sample penelitian ini masuk ke kategori usia optimal untuk memiliki kekuatan otot maksimal, yaitu antara usia 20-35 tahun. Dengan rerata tinggi badan dan berat badan seperti tampak pada tabel 3, rerata Indeks Massa Tubuh dari sample penelitian termasuk dalam kategori overweight atau pre-obese dengan rentang 25,00-29,99 menurut klasifikasi WHO tahun $2004{ }^{6}$

Tabel 4, 5, dan 6 menunjukkan hubungan tingkat kekuatan otot yang diukur dengan push dynamometer, pull dynamometer dan leg dynamometer terhadap prestasi atlet judo. Pada tabel tersebut didapatkan nilai $\mathrm{p}>0,05$ dari hasil analisis uji regresi logistik, yang berarti tidak terdapat hubungan signifikan antara kekuatan otot terhadap prestasi pada atlet Judo pada pelaksanaan PON XVIII 2012 Riau.

Tabel 4 Hubungan Tingkat Kekuatan Otot yang Diukur dengan Push Dynamometer terhadap Prestasi

\begin{tabular}{lccc}
\hline & Variabel & \multicolumn{3}{c}{ Prestasi (n=19) } \\
\cline { 2 - 4 } \multicolumn{1}{c}{ Kategori Kekuatan Otot (Push Dynamometer) } & Berprestasi & Tidak Berprestasi Nilai $\mathbf{~}$ \\
\hline Kurang & 0 & 0 & \\
Cukup & 3 & 4 & 0,764 \\
Baik & 0 & 0 & \\
Baik Sekali & 3 & 7 & \\
Sempurna & 1 & 1 & \\
\hline
\end{tabular}


Tabel 5 Hubungan Tingkat Kekuatan Otot yang Diukur dengan Pull Dynamometer terhadap Prestasi

\begin{tabular}{|c|c|c|c|}
\hline \multirow{2}{*}{$\begin{array}{c}\text { Variabel Kategori Kekuatan Otot (Pull } \\
\text { Dynamometer) }\end{array}$} & \multicolumn{3}{|c|}{ Prestasi $(n=19)$} \\
\hline & Berprestasi & Tidak Berprestasi & Nilai $p$ \\
\hline Kurang & 0 & 1 & \\
\hline Cukup & 3 & 5 & \\
\hline Baik & 0 & 3 & 0,570 \\
\hline Baik Sekali & 4 & 2 & \\
\hline Sempurna & 0 & 1 & \\
\hline
\end{tabular}

Tabel 6 Hubungan Tingkat Kekuatan Otot yang Diukur dengan Leg Dynamometer terhadap Prestasi

\begin{tabular}{lccc}
\hline \multicolumn{2}{c}{ Variabel Kategori Kekuatan Otot $\begin{array}{c}\text { Leg } \\
\text { Dynamometer) }\end{array}$} & \multicolumn{3}{c}{ Prestasi $(\mathbf{n}=19)$} \\
\cline { 2 - 5 } & Berprestasi Tidak Berprestasi Nilai p \\
\hline Kurang & 0 & 1 & \\
Cukup & 0 & 3 & 0,132 \\
Baik & 3 & 3 & \\
Baik Sekali & 4 & 5 & \\
Sempurna & 0 & 0 & \\
\hline
\end{tabular}

\section{DISKUSI}

Pada Tabel 4 hingga Tabel 6 tidak ditemukan hubungan yang signifikan antara kekuatan otot atlet cabang olahraga judo terhadap prestasi yang dicapai. Hal ini tidak sesuai dengan penelitian Todorov et al (2013) dan Novi Sad et al (2015), Serbia, yang menyatakan bahwa atlet judo yang meraih medali (elit) pada kejuaraan judo memiliki kekuatan otot yang lebih tinggi dibandingkan dengan atlet yang tidak meraih medali (subelit).

Tidak ditemukannya hubungan yang signifikan antara kekuatan otot dan prestasi atlit judo dapat disebabkan oleh berbagai hal. Prestasi seorang atlet dapat diraih pada seseorang yang memiliki bakat serta telah menjalani proses pelatihan yang berjenjang dan berkelanjutan. ${ }^{8}$ Disamping hal bakat dan proses pelatihan, terdapat 3 faktor utama agar atlet dapat meraih prestasi yang maksimal, yaitu kondisi kebugaran fisik, teknik atau strategi serta kesiapan mental atlet. ${ }^{8,9}$ Komponen kebugaran fisik selain kekuatan otot mencakup pula faktor daya tahan jantung paru, daya tahan otot, kelentukan, dan komposisi tubuh. ${ }^{9,10}$

Dalam judo, daya tahan jantung paru berperan untuk mengantarkan oksigen secara efektif ke otot sehingga tubuh mampu melakukan aktivitas dinamis seperti membanting atau melempar lawan yang menggunakan kelompok otot besar dengan baik. ${ }^{11}$ Kelentukan juga berperan penting untuk memenuhi kebutuhan sistem neuromuskuler yang besar dalam olahraga kontak fisik seperti judo sehingga atlet dapat melakukan gerakan dengan sempurna. ${ }^{12}$ Bersamaan dengan kekuatan, daya tahan otot juga berperan penting agar praktisi judo mampu menghasilkan dan mempertahankan kekuatan sepanjang pertarungan. ${ }^{13}$ Penelitian Casals et al (2017) menunjukkan bahwa atlet judo yang meraih medali (elit) memiliki komposisi tubuh berupa massa bebas lemak dan massa tulang relatif lebih tinggi yang memberi keuntungan bagi kinerja atlet judo tersebut, oleh karena itu program pelatihan harus meningkatkan massa otot namun sedikit mengurangi atau menjaga lemak tubuh, menunjang prestasi atlet. ${ }^{14}$

Dalam judo kekuatan otot memang memiliki peran utama dalam melaksanakan teknik membanting lawan untuk mencapai keberhasilan dalam pertandingan, ${ }^{2,15}$ namun kekuatan otot juga dipengaruhi oleh beberapa faktor seperti usia dan jenis kelamin, yang juga dinilai mampu mempengaruhi prestasi atlet judo. ${ }^{16}$ Penelitian Skrzek et al (2012) menyatakan variasi usia berpengaruh terhadap kekuatan otot yang dihasilkan. Ditemukan terdapat penurunan nilai kekuatan otot seiring bertambahnya usia. ${ }^{16}$ Pada penelitian ini seluruh sample penelitian berada pada rentang usia 20-35 tahun, yang berdasarkan penelitian Tokarski et al (2012) merupakan rentang usia dimana nilai kekuatan otot mencapai maksimal. ${ }^{17}$ Oleh karena itu, pada penelitian ini, faktor usia tidak 
mempengaruhi prestasi atlet terkait aspek kekuatan otot.

Performa atlet untuk dapat memenangkan pertandingan juga dipengaruhi oleh frekuensi atau dosis latihan yang telah dilakukan, yang tidak dianalisis pada penelitian ini. ${ }^{9}$ Penelitian Serra et al (2017) menunjukkan bahwa dua sampai empat sesi latihan dalam seminggu cukup untuk menghasilkan penguatan otot yang signifikan. Di sisi lain, frekuensi latihan yang lebih tinggi diyakini mampu menghasilkan presentase kekuatan otot yang tinggi. ${ }^{18} \mathrm{Hal}$ ini sesuai dengan penelitian Utami et al di Indonesia yang menyebutkan bahwa frekuensi latihan yang baik untuk olahraga prestasi dilakukan paling sedikit tiga hari per minggu karena ketahanan kondisi fisik seseorang akan turun setelah 48 jam tidak melakukan latihan. ${ }^{9}$ Penelitian Purba et al (2012) mengatakan durasi atau lama latihan bagi atlet untuk memperoleh kekuatan otot yang maksimal dilakukan selama 6 minggu pada tahap awal pelatihan. ${ }^{19}$ Pengambilan data kekuatan otot yang cukup jauh dengan pelaksanaan pertandingan juga dapat mempengaruhi tidak bermaknanya analisis penelitian ini karena tidak dapat menggambarkan hasil latihan sebelum dilakukannya pertandingan.
Tidak bermaknanya hasil penelitian ini dapat pula disebabkan oleh karena terdapatnya berbagai keterbatasan penelitian. Data penelitian yang merupakan data sekunder menyulitkan dikembangkannya analisis yang mendalam untuk mencari kemungkinan faktor lain selain kekuatan otot yang mempengaruhi prestasi atlet judo. Terbatasnya jumlah sampel penelitian juga ikut mempengaruhi interpretasi hasil penelitian dan implementasinya secara umum.

\section{KESIMPULAN}

Tidak terdapat hubungan yang signifikan antara tingkat kekuatan otot dengan prestasi atlet cabang olahraga judo pada PON XVIII 2012 Riau. Untuk meningkatkan validitas dan kemaknaan dari hasil penelitian, maka diperlukan penelitian lebih lanjut pada populasi yang lebih luas dan besar dengan menilai komponen kebugaran fisik lainnya seperti daya tahan jantung paru, daya tahan otot, kelentukan, dan komposisi tubuh serta peran frekuensi atau dosis latihan yang dapat mempengaruhi prestasi atlet.

\section{DAFTAR PUSTAKA}

1. Ucu KR. 2012. Daftar Akhir Perolehan Medali PON Riau, DKI Juara Umum 2012 [Diunduh 2017]; Tersedia dari:

http://www.republika.co.id/berita/olahraga/pek an-olahraga- nasional/12/09/20/manp26-daftarakhir-perolehan-medali-pon-riau-dki- juaraumum.

2. Drid P, Casals C, Mekic A. 2015. Fitness and Anthropometric Profiles of International vs. National Judo Medalists in Half-Heavyweight Category. The $\mathrm{J}$ of Strength and Conditioning Res. 29(8):2115-21.

3. Franchini E, Fukuda DH, Brito C, Artioli GG. 2013. The Physiology of Judo Specific Training Modalities. The $\mathrm{J}$ of Strength and Conditioning Res. 28(5):1-7.

4. Ghrairi M, Hammouda O, Malliaropoulos N. 2014. Muscular Strength Profile in Tunisian Male National Judo Team. Muscles, Ligaments and Tendons J. 4(2):149-53.

5. Organization WH. 2006. BMI classification. Geneva, Switzerland 2006 [Diunduh pada 19 Agustus 2017]; Tersedia dari: http://apps.who.int/bmi/index.jsp?introPage=int ro_3.html.

6. Todorov I, Bratic M, Nurkic M, Radovanovic D. 2013. The Influence of Physiological
Characteristics on The Competitive Success of Judo Athletes. Physical Edu and Sport J. 11(3):317-23.

7. Purba A. 2016. Penerapan Faal Olahraga untuk Prestasi Atlet, Asupan Gizi, Penatalaksanaan Cedera Olahraga Taping. Bandung: Universitas Padjadjaran.

8. Utami D. 2015. Peran Fisiologi dalam Meningkatkan Prestasi Olahraga Indonesia Menuju Sea Games. J Olahraga Prestasi. 11(1):52-61.

9. Tuba M, Defne O, Bilgehan BMS. 2012. Muscle Strength in Relation to Body Composition in the Turkish Male National Judo Team. Sci Movement and Health. XII(2):175182.

10. Katralli J, Itagi V, Goudar SS. 2015. Assessment of Aerobic Capacity and Muscle Strength in Indian Judokas. Internat $\mathrm{J}$ of Physical Edu, Sports and Health. 1(3):35-8.

11. Saraiva AR, Reis VM, Costa PB. 2014. Chronic Effects of Different Resistance Training Exercise Orders on Flexibility in Elite Judo Athletes. J of Human Kinetics. 40:129-37.

12. Barbado D, Valenciano AL, Recio CJ. 2016. Trunk Stability, Trunk Strength and Sport Performance Level in Judo. PLoS ONE. 11(5):1-12. 
14. Casals C, Huertas JR, Franchini E, Przybycien KS, Sterkowicz S, Garcia CG, et al. 2017. Special Judo Fitness Test Level and Anthropometric Profile of Elite Spanish Judo Athletes. The $\mathrm{J}$ of Strength and Conditioning Res. 31(5):1229.

15. Katralli J, Ghoudar SS. 2012. Anthropometric Profile and Special Judo Fitness levels of Indian Judo Players. Asian J of Sports Med. 3(2):1138.

16. Skrzek A, Ignasiak Z, Koziel S, Slawinska T, Rozek K. 2012. Differences in muscle strength depend on age, gender, and muscle functions. Isokinetics and Exercise Sci. 20(3):229-35.

17. Tokarski T, Liu DR, Kaminska J. 2012. The
Influence of Age and Type of Force on Muscle Strength Capabilities in Women. International J of Occup Safety and Ergonomics. 18(1):47-57.

18. Serra R. 2015. The Effects of Resistance Training Frequency on Strength Gains. Res J of the American Soc of Exercise Physiol. 18(1):37-45.

19. Purba, 2012. Prestasi Puncak Atlet Tercapai dengan Menerapkan Iptek Olahraga, Khususnya Ilmu Faal Olahraga. [Diakses pada tanggal 12 Desember 2012]. Tersedia dari: http://www.unpad.ac.id/profil/prof-drambrosius-purba-dr-m-sc-aifo-jika-inginberprestasi-iptek-olah-raga-harus-betul-betulditerapkan/ 